\title{
Erratum to: Topsoil Carbon Stock and Soil Physicochemical Properties in Riparian Forests and Agricultural Lands of Southwestern Iran
}

\author{
M. Forogh $\operatorname{Nasab}^{a}$, M. Moradi ${ }^{a, ~ *}$, Gh. Moradi ${ }^{b}$, and R. Taghizadeh-Mehrjardic, $d$ \\ ${ }^{a}$ Department of Forestry, Faculty of Natural Resources, Behbahan Khatam Alanbia University of Technology, \\ Khuzestan, P.O. Box 6361647189 Iran \\ ${ }^{b}$ School of Natural Resources and Desert Studies, Yazd University, Yazd, P.O. Box 89168-69511 Iran \\ ${ }^{c}$ Faculty of Agriculture and Natural Resources, Ardakan University, Yazd, P.O. Box 89518-95491 Iran \\ ${ }^{d}$ Department of Geosciences, Soil Science and Geomorphology, University of Tübingen, Tübingen, Germany \\ *e-mail:moradi4@gmail.com \\ Submitted February 15, 2021; accepted for publication February 15, 2021
}

DOI: $10.1134 / \mathrm{S} 1064229321300013$

The name of the fourth author should read R. Taghizadeh-Mehrjardi Copyright of the article should read as follows:

(C) Pleiades Publishing, Ltd., 2020, corrected publication 2021

The original article can be found online at https://doi.org/10.1134/S1064229320100075

The original article has been corrected. 